\title{
Re: Prevalence and Risk Factors of Infertility in Turkey: Evidence from Demographic and Health Surveys, 1993-2013
}

\author{
Sarac M, Koc I \\ Hacettepe University, Institute of Population Studies, Ankara, Turkiye \\ J Biosoc Sci. 2018;50:472-490. doi: 10.1017/S0021932017000244. Epub 2017 Jun 23.
}

\section{EDITORIAL COMMENT}

In recent years, in Turkish media and general population, infertility has gained increasing interest and, mostly, it is believed that the prevalence is increasing. In this study, the authors aimed to understand the changes in the prevalence of infertility in the last 20 years. They used the data of Demographic and Health Surveys (DHS) performed between 1993 and 2013. Three different approaches were used for this purpose: the DHS approach estimating infertility prevalence among women who have been married for at least 5 years; the constructed approach estimating infertility within the 12 months before the survey date; and the current duration approach focusing on the time from when a couple starts to attempt pregnancy until it occurs. Surprisingly, this study showed that the infertility rate in Turkey has declined from 15\% in 1993 to 8.1\% in 2013. However, the percentage of women who have used assisted reproductive technology (ART) at least once increased from 1.9\% in 2008 to $4.2 \%$ in 2013. The authors believed that increasing number of ARTs in recent years was the result of incentives provided by the Turkish government for the treatment of infertility and a decline in taboos about infertility and its treatment.

Emre Bakırcıoğlu, MD

๑Copyright 2018 by the Association of Urological Surgery / Journal of Urological Surgery published by Galenos Publishing House. 